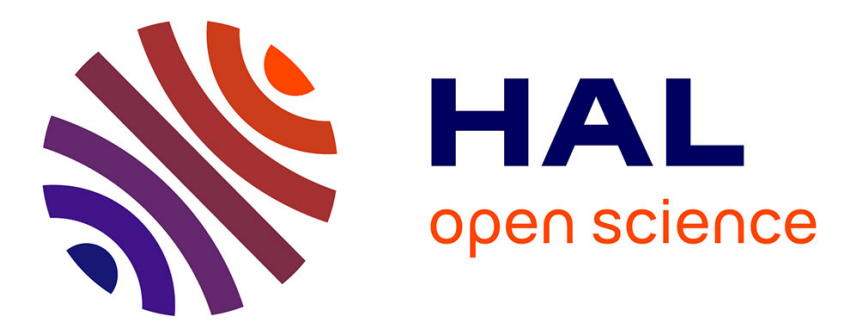

\title{
Optimization of low voltage metallized film capacitor geometry
}

Yannick Vuillermet, Olivier Chadebec, J.M. Lupin, A. Saker, Gérard Meunier, Jean-Louis Coulomb

\section{- To cite this version:}

Yannick Vuillermet, Olivier Chadebec, J.M. Lupin, A. Saker, Gérard Meunier, et al.. Optimization of low voltage metallized film capacitor geometry. IEEE Transactions on Magnetics, 2007, 43 (4), pp. 1569-1572. 10.1109/TMAG.2007.892473 . hal-00283320

\section{HAL Id: hal-00283320 https://hal.science/hal-00283320}

Submitted on 27 Jun 2008

HAL is a multi-disciplinary open access archive for the deposit and dissemination of scientific research documents, whether they are published or not. The documents may come from teaching and research institutions in France or abroad, or from public or private research centers.
L'archive ouverte pluridisciplinaire HAL, est destinée au dépôt et à la diffusion de documents scientifiques de niveau recherche, publiés ou non, émanant des établissements d'enseignement et de recherche français ou étrangers, des laboratoires publics ou privés. 


\title{
Optimization of Low-Voltage Metallized Film Capacitor Geometry
}

\author{
Y. Vuillermet ${ }^{1}$, O. Chadebec ${ }^{1}$, J. M. Lupin ${ }^{2}$, A. Saker ${ }^{2}$, G. Meunier ${ }^{1}$, and J.-L. Coulomb ${ }^{1}$ \\ ${ }^{1}$ Ecole d'ingénieurs en Energie et Traitement de l'Information-INP Grenoble (ENSIEG), 38402 Saint Martin d'Hères Cedex, \\ Grenoble, France \\ ${ }^{2}$ Rectiphase-Schneider Electric, 74370 Pringy, France
}

\begin{abstract}
Thermal constraint is one of the major cause of capacitor failures. In this paper, a loss model, based on electrode current distribution, is first established to determine, by numerical simulation, a temperature mapping of capacitor. This mapping is successfully compared to measurements. Then a shape optimization, coupling losses computing and finite-element method, is led in order to find parameters that give the best lifespan and the larger reactive power provided. Very interesting new geometries have been found out; they allow an increase in reactive power greater than the increase in volume.
\end{abstract}

Index Terms-Capacitor lifespan, capacitor losses, metallized film capacitors, shape optimization.

\section{INTRODUCTION}

L OW-VOLTAGE metallized film capacitors main uses are reactive energy compensation and harmonic filtering. They are made of two polypropylene films coated with zinc of few nanometer's thickness and rolled together, with a small offset, over an isolated hollow support (mandrel) (see Fig. 1) [1], [2]. Each film is then short-circuited by zinc sprayed on each side of the capacitor; this process is called the shooping. Metallization of capacitors used in this study consist in layers of complex shape (see Figs. 1 and 2) and thin enough to enable self-healing of defaults [3]. Many phenomena are involved in the aging of such capacitor (electrical, dielectric, thermal, chemical, and physical aging for example), that is why it is very difficult to set up a life model. Some studies [4] have already searched for the factors that may cause an accelerated aging, and some works have shown the effects of geometry on metallized film capacitor's heating [5], [6]. However, no optimizations have really been led.

During use, heating occurs mainly because of resistive and dielectric losses. As overheating decreases dielectric performance and as self-healing property increases with thin metallization (that increases resistive losses and overheating); a compromise has to be found out between metallization thickness and dielectric performance. It partially explains the shape of metallization that try to unite advantages of thin metallization (i.e., good self-healing) and of thick metallization (i.e., low losses).

The aim of this study is to improve lifespan and to increase reactive power provided by capacitor.

Digital Object Identifier 10.1109/TMAG.2007.892473

Color versions of one or more of the figures in this paper are available online at http://ieeexplore.ieee.org.

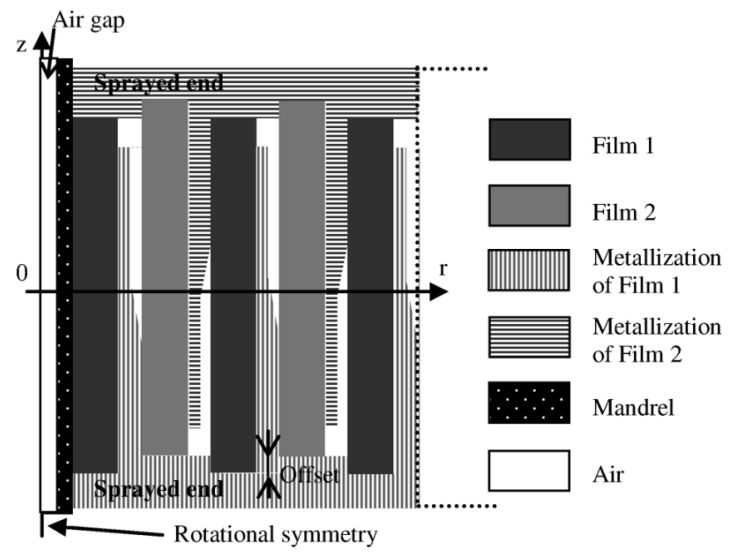

Fig. 1. Two-dimensional cross-sectional view of a metallized film capacitor.

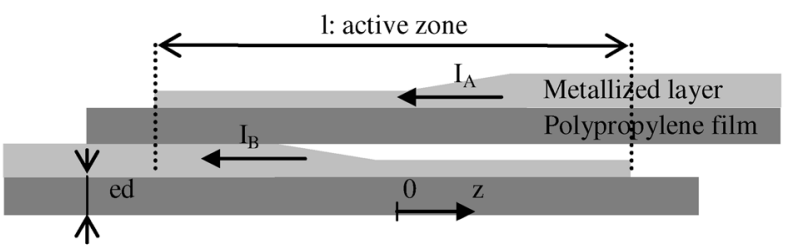

Fig. 2. View of a basic element of capacitor.

\section{CAPACITOR MODELling}

\section{A. Loss Model}

Loss model calculation of constant metallization capacitor is quite classical [2]. However, the loss model described below is an original improvement to take into account nonconstant metallization.

Considering a part of the capacitor (called a basic element in the following), consisting in two layers of films and two metal- 
lized layers (see Fig. 2), the current of plate $\mathrm{A} I_{A}$, along $z$ axes, is solution of the differential equation

$$
\begin{aligned}
\frac{d^{2} \underline{I_{A}}}{d z^{2}}(z)-\frac{4 \pi \omega j \varepsilon_{0} \varepsilon_{r}}{e_{d}}[R(z)+ & R(-z)] \underline{I_{A}}(z) \\
& =-\frac{1}{2} \frac{4 \pi \omega j \varepsilon_{0} \varepsilon_{r}}{e_{d}} R(-z) \underline{I}
\end{aligned}
$$

where $R$ is the resistance of the layer depending on the shape of the layer, $\mathrm{e}_{d}$ the dielectric thickness, $\varepsilon_{0}, \varepsilon_{r}$ are the vacuum and relative permittivity, $\omega$ is the pulsation, and $I$ the excitation current.

This differential equation, that governs current repartition in each plate, is obtained as in [2]. However and contrary to what was done in [2], it was here necessary to take into account the fact that the thickness of the metallization is not constant.

Equation (1) must be solved in each part of the active zone (i.e., where there is effectively a capacitor effect) with the corresponding resistances. Solutions of this equation can be found using Airy functions [7], [8]. These functions form a pair of linearly independent solutions to

$$
\frac{d^{2} W}{d z^{2}}-z W=0
$$

They can be expressed thanks to modified Bessel functions as

$$
\begin{aligned}
& A i(z)=\frac{\sqrt{z / 3}}{\pi} K_{1 / 3}\left(2 / 3 z^{3 / 2}\right) \\
& B i(z)=\sqrt{z / 3}\left(I_{-1 / 3}\left(2 / 3 z^{3 / 2}\right)+I_{1 / 3}\left(2 / 3 z^{3 / 2}\right)\right) .
\end{aligned}
$$

From this point, there is no analytical expression for the current that is why the numerical functions $\eta_{\mathrm{IA}}(z), \eta_{I B}(z), \eta_{V}(z)$, depending on Airy functions, are introduced. They are continuous but defined in each part of the active zone. Thus current in each plate $I_{A}$ and $I_{B}$ and electrical potential $\mathrm{V}$ can be expressed thanks to $\eta_{I A}, \eta_{I B}, \eta_{V}$ as

$$
\begin{aligned}
\underline{I_{A}}(z) & =1 / 2 \eta_{I A}(z) \underline{I} \\
\underline{I_{B}}(z) & =1 / 2 \eta_{I B}(z) \underline{I} \\
\underline{V}(r, z) & =1 / 2 \eta_{V}(z) \underline{I} / r
\end{aligned}
$$

where $r$ is the radius of the basic element.

Losses per volumetric unit are described by the sum of resistive losses [first term of (8)] and dielectric losses (second term)

$$
\begin{aligned}
& P_{v}(r, z)=\frac{Y_{0}^{2} U^{2}}{4 \pi \times e_{d}} \eta_{\Omega}(z)-\frac{Y_{0}^{2} U^{2}}{4 \pi \times e_{d}} \tan \delta \times \eta_{Q}(z) \\
& P_{v}(r, z)=\frac{Y_{0}^{2} U^{2}}{4 \pi \times e_{d}}\left[\eta_{\Omega}(z)-\tan \delta \times \eta_{Q}(z)\right]
\end{aligned}
$$

where $\delta$ is the dielectric loss angle at the working frequency, $U$ the applied voltage, and

$$
\begin{aligned}
\underline{\eta_{\Omega}}(z) & =\left(R(z)\left|\eta_{I A}(z)\right|^{2}+R(-z)\left|\eta_{I B}(z)\right|^{2}\right) I^{2} \\
\underline{\eta_{Q}}(z) & =-\frac{4 \pi \omega \varepsilon_{0} \varepsilon_{r}}{e_{d}}\left|\eta_{V}(z)\right|^{2} \\
\underline{Y_{0}} & =\frac{j C_{0} \omega}{1+j R_{0} C_{0} \omega}
\end{aligned}
$$

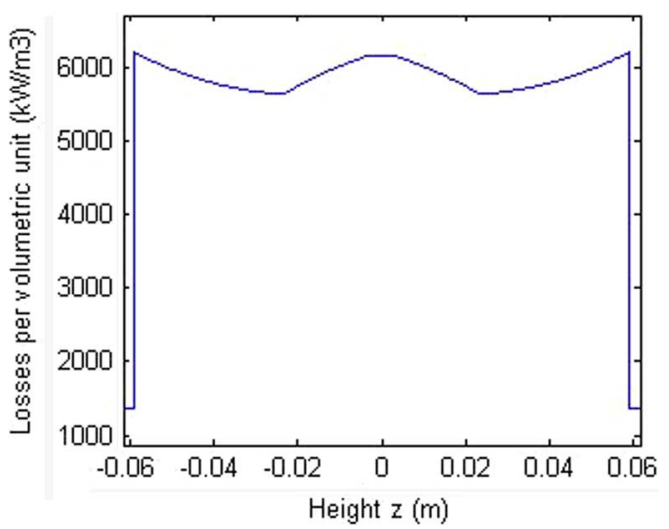

Fig. 3. Losses per volumetric unit inside existing capacitor versus height $z$.

$$
\begin{aligned}
& R_{0}=\int_{-l / 2}^{l / 2} \eta_{\Omega}(z) d z-\tan \delta\left(\int_{-l / 2}^{l / 2} \eta_{Q}(z) d z\right) \\
& C_{0}=-\left(\omega \int_{-l / 2}^{l / 2} \eta_{Q}(z) d z\right)^{-1} .
\end{aligned}
$$

One can notice that losses in the basic element do not depend on radius $r$. The losses inside existing capacitor are shown in Fig. 3.

\section{B. Thermal Mapping}

To obtain the thermal mapping, (15) is to be solved with the appropriate boundary conditions

$$
\operatorname{div}(\overline{\bar{\lambda}} \cdot \overrightarrow{\operatorname{grad}}(T))+P_{v}=0
$$

where $\lambda$ is the thermal conductivity, $T$ the temperature, and $P_{v}$ the losses defined previously.

This equation is solved by finite-element software Flux3D. It is of course impossible to describe thousands layers of metallized film, so a homogenization method is used to replace layers by a single material with anisotropic thermal properties [5]. In addition, convection and radiation heat transfer (i.e., boundary conditions) are considered as in [5].

The thermal mapping is presented on Fig. 4. The whole package has been simulated, i.e., the metallized film and the mandrel but also the connections and the mechanical support.

Numerical results have been compared to measurements (on existing capacitors) at different voltages and at four different locations. Errors between thermal mapping and measurements appeared to be lower than $10 \%$ (see Table I).

\section{Thermal Influence of the Air-Gap}

If the effects of thermal convection in the air-gap were neglected in the previous thermal mapping (because of its small thickness), they could not be during optimization. Indeed, the air-gap thickness increases when mandrel's radius increases. The effects of convection have been estimated thanks to software Flotherm (that solves thermal and fluid mechanics problem). The dielectric's overheating due to the convection has been expressed versus the height of the capacitor and the mandrel's radius (see Fig. 5). 


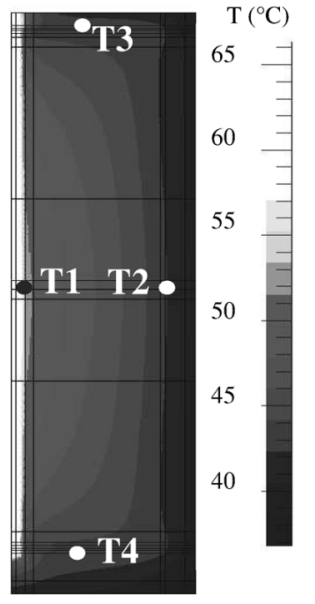

Fig. 4. Thermal mapping of existing capacitor and sensors position ( $U=$ $421 \mathrm{~V}$, environment temperature is $\left.32^{\circ} \mathrm{C}\right)(2$-D cross-sectional view).

TABLE I

ERROR BETWEEN THERMAL MODEL AND EXPERIMENTS

\begin{tabular}{ccc}
\hline Sensor & $\begin{array}{c}\text { Error in }{ }^{\circ} \mathrm{C} \\
(\text { voltage }=421 \mathrm{~V})\end{array}$ & $\begin{array}{c}\text { Error in }{ }^{\circ} \mathrm{C} \\
(\text { voltage }=515 \mathrm{~V})\end{array}$ \\
$\mathrm{T} 1$ & 0 & 0 \\
$\mathrm{~T} 2$ & $+0,5$ & +1.0 \\
$\mathrm{~T} 3$ & +1.0 & -1.0 \\
$\mathrm{~T} 4$ & -1.0 & $-0,5$ \\
\hline
\end{tabular}

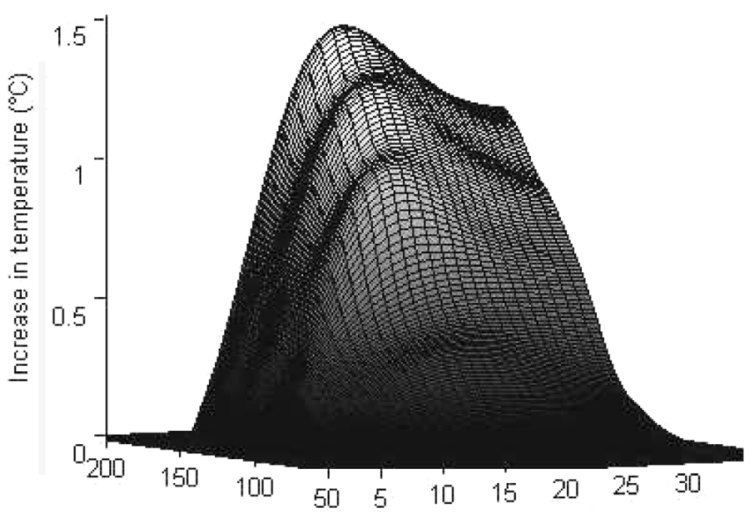

Height of the metallized film (mm) Thickness of the air gap ( $(\mathrm{mm})$

Fig. 5. Dielectric's overheating versus the height of the capacitor versus mandrel's radius.

\section{SHAPE OPTIMIZATION}

\section{A. Optimization Method}

Lifespan is very hard to evaluate [4], [6], but it is known to be strongly linked to dielectric's temperature. That is why, in a first optimization, maximum dielectric's temperature is minimized in order to increase lifespan. In a second optimization, reactive power provided is maximized and maximum dielectric's temperature is kept equal to the value of existing capacitors (thus the lifespan is also considered constant). In every optimization, the volume is minimized (economical criterion) and some constraints are added to limit research space size. So the optimization is a constrained multiobjectives one.

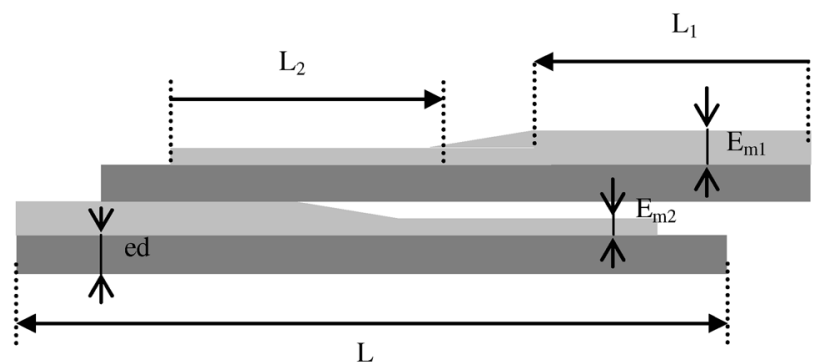

Fig. 6. Optimization parameters

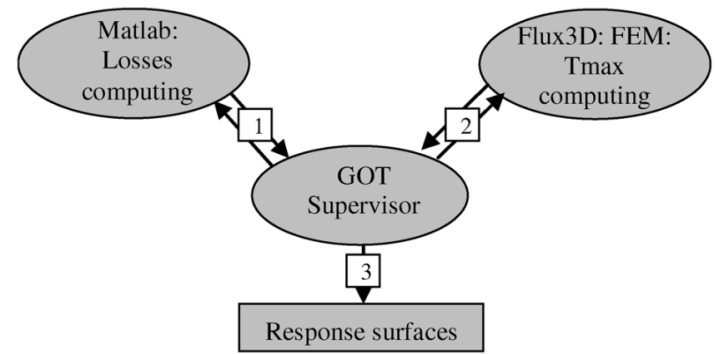

Fig. 7. Steps of the response surfaces construction.

Thanks to the previous model, losses and maximum dielectric temperature are known whatever the capacitor's geometry is. So a shape optimization can now be done.

The parameters are as follows (see Fig. 6):

$-L_{1}$ : length of the thick part of metallization;

$-L_{2}$ : length of the thin part of metallization;

- L: length of the dielectric film;

$-E_{m 1}$ : thickness of the thick part of metallization;

$-E_{m 2}$ : thickness of the thin part of metallization;

$-e_{d}$ : dielectric film thickness;

$-R$ : Mandrel's radius.

Considering the number of parameters and simulation time, numerical design of experiment are used. A supervisor, called general optimization tools (GOTs), is used to synchronise each step of the computation, to build response surfaces and to optimize them. First, a GOT sends geometry data to Matlab that computes losses in every part of the capacitor and returns them to the supervisor (step 1 on Fig. 7). Then the GOT sends geometry data and losses to FEM software Flux3D that modifies the capacitor geometry and meshes it. The physical data are also changed and finally Flux3D runs computation. The dielectric maximal temperature, associated to this geometry, is returned to a GOT that stores it (step 2). These steps are repeated until all geometries given by parameters' range have been simulated. From the geometries and the temperatures stored, a GOT builds response surfaces based on radial basis functions [9] (step 3) (see an example in Fig. 8).

Multiobjectives optimization is led on response surfaces by genetic algorithms and finally Pareto surfaces [10] are obtained.

\section{B. Dielectric's Temperature Minimization}

The main aim of the first optimization is to minimize maximum dielectric temperature in order to increase lifespan. The method described above is run and Pareto surfaces are obtained.

Among the solutions given by Pareto surfaces, two sets of parameters have been selected: the first one provides the best 


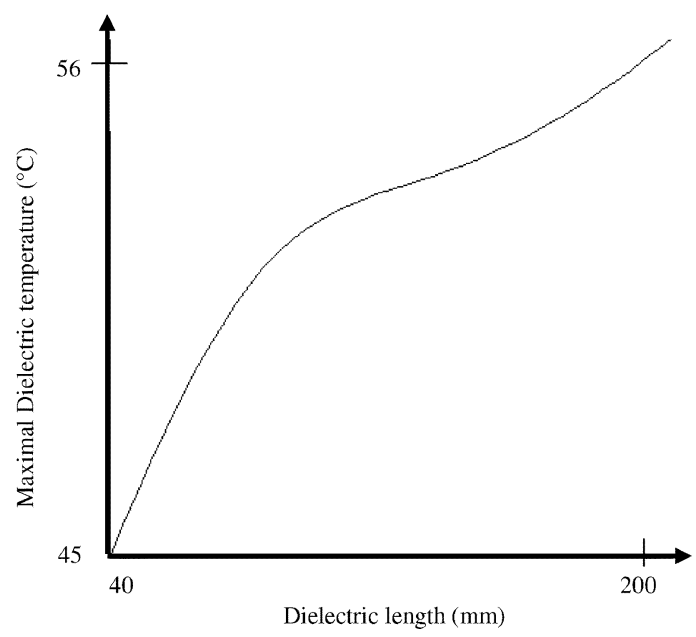

Fig. 8. Maximal dielectric temperature versus dielectric length.

TABLE II

DIELECTRIC'S TEMPERATURE MINIMIZATION: INCREASES COMPARED TO EXISTING CAPACITOR

\begin{tabular}{ccc}
\hline Capacitors & Decrease in & Increase in \\
& temperature & volume \\
1 & $4,0^{\circ} \mathrm{C}$ & $22 \%$ \\
2 & $3,5^{\circ} \mathrm{C}$ & $18 \%$ \\
\hline
\end{tabular}

TABLE III

REACTIVE POWER MAXIMIZATION: INCREASES COMPARED TO EXISITNG CAPACITOR

\begin{tabular}{ccc}
\hline Capacitors & Increase in & Increase in \\
& reactive power & volume \\
3 & $55 \%$ & $61 \%$ \\
4 & $16 \%$ & $5 \%$ \\
5 & $34 \%$ & $23 \%$ \\
\hline
\end{tabular}

decrease in temperature (about 10\%) and the second one is the best compromise between temperature and volume objectives (see Table II). One can notice that it is impossible to decrease temperature at constant volume; it means that existing capacitor was well-designed (without any optimization technique).

\section{Reactive Power Maximization: Indirect Inversion of FEM Problem}

Optimization's objectives are now to increase reactive power and to minimize volume. Maximum dielectric's temperature $T_{\max }$ is kept equal to the value of existing capacitors. The key point is that it is very difficult to inverse FEM (i.e., to find parameters that give the wanted temperature $T_{\max }$ ). The method used here consists in building response surfaces as previously (i.e., it means that capacitor with maximum temperature different than $T_{\max }$ are computed) and then to constrain optimization in temperature. Thus optimization's results are capacitors with the wished maximum temperature but with different geometries and different reactive power provided.

Among the solutions three new capacitors have been selected: the first one provides the maximum reactive power, the second one has the best increase in reactive power/increase in volume ratio and the last one is a good compromise (see Table III). The two last capacitors are particularly interesting because the increase in reactive power is greater than the increase in volume.

\section{CONCLUSION}

Original methods are discussed in this paper. First, a calculation of losses for a nonconstant metallization is developed. Then optimizations coupling Matlab and finite-element method are set up. If the first optimization is rather classical, the second one is an original point of view to inverse finite-element method. Notice that this shape optimization method could be used for a various range of system. To conclude this study, it could be very interesting to test experimentally the capacitors obtained.

\section{ACKNOWLEDGMENT}

This work was supported by Rectiphase-Schneider Electric.

\section{REFERENCES}

[1] "Condensateurs utilisés en électronique de puissance," Technique de l'ingénieur, 1995, D4 II D644.

[2] C. Joubert, "Etude des phénomènes Electromagnétiques dans les condensateurs à films métallisés-Nouvelles génération de condensateurs," Ph.D. dissertation, Ecole Centrale de Lyon, Lyon, France, 1996.

[3] C. W. Reed and S. W. Cichanowski, "The fundamentals of aging in HV polymer-film capacitors," IEEE Trans. Dielectr. Elect. Insul., vol. 1 , no. 5, pp. 904-922, 1994.

[4] G. C. Montanari and D. Fabiani, "Searching for the factors which affect self-healing capacitor degradation under non-sinusoidal voltage," IEEE Trans. Dielectr. Elect. Insul., vol. 6, no. 3, pp. 319-325, 1999.

[5] M. H. El-Husseini, P. Venet, G. Rojat, and C. Joubert, "Thermal simulation for geometric optimization of metallized polypropylene film capacitors," IEEE Trans. Ind. Appl., vol. 38, pt. 3, pp. 713-718, 2002.

[6] M. H. El-Husseini, P. Venet, G. Rojat, and M. Fathallah, "Effect of the geometry on the aging of metallized polypropylene film capacitor," in Proc. 32nd Ann. IEEE Power Electronics Specialists Conf. (PESC. 2001), 2001, vol. 4, pp. 2061-2066.

[7] R. Demersseman, "Modélisation du comportement électrique de condensateurs basse tension," D.E.A. dissertation, D.S.T. Schneider Electric Grenoble, Lab. d'Electrotech. de Grenoble, Grenoble, France, 2004.

[8] M. Abramovitz and I. A. Stegun, Handbook of Mathematical Functions. New York: Dover, 1965

[9] P. Alotto, M. Gaggero, G. Molinari, and M. Nervi, "A design of experiment and statistical approach to enhance the generalised response surface method in the optimization of multiminima problem," IEEE Trans. Magn., vol. 33, no. 2, pp. 1896-1899, Mar. 1997.

[10] J. L. Coulomb, "Optimisation," in Electromagnétisme et Problèmes Couplés. Hermès, France: traité EGEM, 2002, ch. 8.

Manuscript received April 30, 2006 (e-mail: Yannick.Vuillermet@leg.ensieg. inpg.fr). 